\section{AB0550 CLINICAL-EPIDEMIOLOGICAL FEATURES OF PATIENTS WITH A LATE-ONSET LUPUS IN A TERTIARY CARE HOSPITAL}

A. Crespo Golmar, C. Moriano, M. Garijo, C. Iñiguez, I. González, A. López, E. Díez, C. Álvarez, M. Martín, E. Vallejo, T. Pérez. Rheumatology Department, University Health Care Complex of León, León, Spain

Background: Different frequency of clinical and serological manifestations has been detected according to the age of onset of the patients with Systemic lupus erythematosus (SLE). According to the literature, senile SLE manifests between $6 \%$ and $18 \%$ of the patients with lupus.

Objectives:

1. To identify and analyse the clinical-serological and epidemiological features of senile SLE in our environment.

2. To determine the average survival time and mortality in these patients, identifying its main cause.

Methods: Observational retrospective study of 319 patients diagnosed with SLE (according to ACR 1992 and SLICC 2012 criteria) at the Hospital of León between 1997-2017 and with an age of onset $\geq 65$ years, obtaining a total of 68 patients with senile SLE.

Results: The mean age at diagnosis was $75.4 \pm 12.1$ years, with a female/male ratio of 2.4. The most frequent manifestations were as joint (63.2\%) and haematological manifestations in the form of leuco-lymphopenia (55.9\%). The hemolytic anaemia only appeared in $2.9 \%$ of the cases and the thrombocytopenia in $25 \%$. $36.8 \%$ of patients showed photosensitivity and $29 \%$ had other cutaneous manifestations, being the malar erythema the most prevalent type (60\%), followed by the discoid lupus erythematosus $(20 \%)$ and the subacute lupus (15\%). Alopecia was only observed in $4.4 \%$. Lupus nephritis was detected in the form of proteinuria in $4.4 \%$ of the patients, and only one patient had microscopic haematuria. Lung involvement was uncommon (8.8\%), taking precedence the UIP (33.3\%) over the rest of the pulmonary manifestations. Only $11.1 \%$ of the patients with senile SLE had serositis, being in the form of pleuritis in $75 \%$ of the cases, pericarditis in the $37.5 \%$ and ascites in the $12.5 \%$. Regarding the neurological involvement, 5 patients showed polyneuropathy and 1 had chorea. Likewise, the frequency of Sjögren, Raynaud and secondary antiphospholipid syndrome was of $16.7 \%$, respectively.

The most important serological findings were: $97.3 \%$ ANA; $44.1 \%$ DNA and $20.6 \%$ hypocomplementemia, with $54.4 \%$ of the patients having serological activity. Only $5.9 \%$ had anti-Sm. Antiphospholipid antibodies were positive in $41.2 \%$ of the cases, with $4.4 \%$ of them showing triple positivity.

The average survival time was of 13.7 years (SD: 10.9-16.5). Out of the total patients, 14 died (20.59\%), mostly due to infectious etiology (35.7\%) and $14.28 \%$ due to disease activity. Other less common causes were neoplasia or ischaemic heart disease (7.14\% respectively)

Conclusions:

- The late-onset SLE prevails in our environment, one of every 5 patients diagnosed with SLE in our consulting room is older than 65 years.

- It is found most often in women and it is confirmed a lower male/female ratio than expected.

- Joint and haematology manifestations and cutaneous involvement in the form of malar erythema define the clinical profile of our patients with senile SLE, with the renal involvement or the presence of serositis being uncommon.

- Half of the patients had serological activity at the onset, having hypocomplementemia only in 1 out of 5 cases.

- Infections were the first cause of mortality in our sample with an average survival time of around 13 years.

Disclosure of Interest: None declared

DOI: 10.1136/annrheumdis-2018-eular.7538

\section{AB0551 OBSTETRICAL MORBIDITY RELATED TO ANTI-SSA ANTIBODIES: DATA FROM A FRENCH MONOCENTRIC RETROSPECTIVE STUDY}

L. Plaçais ${ }^{1}$, F. Carrat ${ }^{2}$, L. Carbillon ${ }^{3}$, P. Nicaise ${ }^{4}$, A. Benbara ${ }^{5}$, O. Fain ${ }^{1}$, A. Mekinian ${ }^{1}{ }^{1}$ Internal Medicine; ${ }^{2}$ Epidemiology and Public health, Saint Antoine hospital; ${ }^{3}$ Obstetrics and Gynecology, Jean Verdier hospital; ${ }^{4}$ Auto-immunity and hypersensibility, Bichat hospital, ${ }^{5}$ Obstetrics and Gynaecology, Jean Verdier hospital, Paris, France

Background: Obstetrical morbidity is an issue among autoimmune diseases patients. Anti-SSA positivity is well known for it's effect on fetus and risk of congenital heart block but no evidence has been yet found for its effect on obstetrical morbidity

Objectives: To investigate anti-SSA positivity effect among a large monocentric cohort of obstetrical morbidity patients and to evaluate the efficacity of different treatment regimens

Methods: All women who were seen from January 2010 to January 2015 in JeanVerdier University Hospital for obstetrical morbidities were retrospectively included. All patients had been tested for anti-nuclear antibodies and anti-SSA/Ro and anti-SSB/La antibodies.

Results: We included 244 women (median age 34 years [interquartile range $21-$ 53]) with 869 pregnancies overall. In 27 (11\%) patients with anti-SSA antibodies, the median age at the time of pregnancy was $29.5(17-40)$ years, with mean number of 3.66 pregnancies per woman. For these 27 patients, 83/99 pregnancies (84\%) had an adverse obstetrical outcome: fetal loss ( $n=65$; at a median of 20 (438) weeks' gestation), preeclampsia $(n=15)$, intrauterine growth restriction $(n=7)$, prematurity $(n=7)$, and congenital heart block $(n=2)$. In comparing women with obstetrical antiphospholipid syndrome and unexplained adverse complications, there was no major difference in frequency of recurrent miscarriages, preterm deliveries, preeclampsia or fetal loss. Among factors associated with obstetrical outcome and fetal loss, aspirin and hydroxychloroquine treatments were significantly associated with a favourable obstetrical outcome: odds ratio $0.05[95 \%$ confidence interval $0.01 ; 0.37](\mathrm{p}=0.003)$ and $0.15[0.02 ; 0.98](\mathrm{p}=0.04)$.

Conclusions: Women with unexplained recurrent obstetrical complications should be screened for anti-SSA antibodies. The benefit of aspirin and hydroxychloroquine treatment to improve the obstetrical outcome should be confirmed in prospective studies.

Disclosure of Interest: None declared

DOI: 10.1136/annrheumdis-2018-eular.5580

\section{AB0552 THE CLINICAL AND LABORATORY FEATURES OF ANTIPHOSPHOLIPID ANTIBODY POSITIVE PATIENTS WITH OR WITHOUT SYSTEMIC LUPUS ERYTHEMATOSUS}

A. Yazici ${ }^{1}$, A. Omma ${ }^{2}$, S. Yilmaz ${ }^{3}$, S. Yavuz ${ }^{4}$, K. Ayar ${ }^{5}$, E. Kasapoglu ${ }^{6}$, B. Kisacik ${ }^{7}$, A. Cefle ${ }^{1}$, D. Erkan ${ }^{8} .{ }^{1}$ Rheumatology, Kocaeli University School of Medicine, Kocaeli; ${ }^{2}$ Rheumatology, Numune Hospital; ${ }^{3}$ Rheumatology, Gulhane Training and Research Hospital, Ankara; ${ }^{4}$ Rheumatology, Bilim University School of Medicine, Istanbul; ${ }^{5}$ Rheumatology, University of Health Sciences Yüksek ihtisas Training and Research Hospital, Bursa; ${ }^{6}$ Rheumatology, Göztepe Training and Research Hospital, Istanbul; ${ }^{7}$ Rheumatology, Medicalpark Hospital, Gaziantep, Turkey; ${ }^{8}$ Barbara Volcker Center for Women and Rhumatic Diseases, Hospital for Special Surgery, Weill Cornell Medicine, New York, USA

Background: A multicenter antiphospholipid antibody (aPL) clinical database was created in 2016 with the pariticipation of six rheumatology centres around the country. The purpose has been to better define aPL-related clinical manifestations and management strategies; and also to establish a resource for future clinical studies.

Objectives: In this first analysis, we compared the clinical and laboratory features of aPL-positive patients with and without systemic lupus erythematosus (SLE). Methods: The demographic, clinical, laboratory, treatment characteristics of the aPL-positive patients with/without other systemic autoimmune diseases (SAID) are recorded at enrollment according to a predefined protocol. The inclusion criteria are positive aPL (lupus anticoagulant test [LA], anticardiolipin antibody [aCL], and/or anti $\beta_{2}$-glycoprotein-I antibody [a $\left.\beta_{2} \mathrm{GPI}\right]$ ) based on the Updated Sapporo Antiphospholipid Syndrome (APS) Classification Criteria at least twice within one year prior to enrolment. ${ }^{1,2}$ For the purpose of this analysis, we only included aPLpositive patients without other autoimmune diseases (primary aPL/APS) and aPLpositive SLE patients (SLE aPL/APS).

Results: As of January 2018, 105 aPL-positive patients were recruited (mean age: $42.6 \pm 10.1$ [min-max: 19-70]; 83 [79\%] female; and 67 [64\%] with another SAID). Ten patients were excluded from the analysis due to their SAID history other than SLE. Of the remaining 95 patients, $38(40 \%)$ had primary aPL/APS; 57 (60\%) fulfilled the ACR SLE Classification Criteria; 42 (44\%) had thrombotic APS (TAPS) (8 arterial, 24 venous, and 8 both); 21 (22\%) had obstetric APS (OAPS) $22(23 \%)$ had both TAPS and OAPS (7 arterial, 14 venous, and 1 both); and 10 (11\%) had no TAPS/OAPS. Fifty percent of the patients had history of at least one non-criteria aPL-manifestation. Demographics, clinical and laboratory manifestations, and medications were similar between primary aPL/APS and SLE aPL/APS patients except increased frequency of autoimmune hemolytic anaemia, aCL IgG, and hydroxychloroquine use in SLE aPL/APS patients (table 1). 
Abstract AB0552 - Table 1

\begin{tabular}{|c|c|c|c|}
\hline $\mathrm{n}(\%)$ & $\begin{array}{c}\begin{array}{c}\text { Primary aPL/APS } \\
n=38\end{array} \\
\end{array}$ & $\begin{array}{c}\begin{array}{c}\text { SLE aPL/APS } \\
n=57\end{array} \\
\end{array}$ & $\mathbf{p}$ \\
\hline $\begin{array}{l}\text { Mean Age } \\
(\min -\max )\end{array}$ & $\begin{array}{c}41.7 \pm 10.5 \\
(24-65)\end{array}$ & $\begin{array}{c}42.9 \pm 10.0 \\
(19-70)\end{array}$ & 0.57 \\
\hline Female & $28(74)$ & $47(83)$ & 0.3 \\
\hline $\begin{array}{l}\text { Thrombosis } \\
\text { Arterial } \\
\text { Venous } \\
\text { Arterial and venous } \\
\text { Transient Ischemic Attack }\end{array}$ & $\begin{array}{l}18(47) \\
4(10) \\
9(24) \\
4(10) \\
3(8)\end{array}$ & $\begin{array}{c}24(42) \\
4(7) \\
15(26) \\
4(7) \\
7(12)\end{array}$ & $\begin{array}{l}0.61 \\
0.55 \\
0.77 \\
0.55 \\
0.49\end{array}$ \\
\hline Pregnancy Morbidity* & $10(26)$ & $11(29)$ & 0.42 \\
\hline $\begin{array}{l}\text { Non-criteria aPL Manifestations } \\
\text { Livedo Reticularis } \\
\text { Thrombocytopenia } \\
\text { Hemolytic Anemia } \\
\text { Valvular Heart Disease } \\
\text { Chronic Skin Ulcer } \\
\text { Biopsy proven aPL nephropathy } \\
\text { White Matter Changes }\end{array}$ & $\begin{array}{c}18(47) \\
6(16) \\
7(18) \\
0 \\
8 / 32(25) \\
2(5) \\
2(5) \\
3 / 25(12)\end{array}$ & $\begin{array}{c}30(53) \\
6(11) \\
12(21) \\
11(19) \\
13 / 55(24) \\
3(5) \\
2(4) \\
11 / 46(24)\end{array}$ & $\begin{array}{c}0.12 \\
0.45 \\
0.75 \\
0.004^{*} \\
0.43 \\
1.0 \\
0.68 \\
0.23\end{array}$ \\
\hline Positive Lupus Anticoagulant & $22 / 35(63)$ & $33 / 57$ (58) & 0.79 \\
\hline $\begin{array}{l}\text { Positive aCL ( } \geq 40 \mathrm{GPL} / \mathrm{MPL} \text { ) } \\
\text { IgG } \\
\text { IgM }\end{array}$ & $\begin{array}{l}25 / 37(68) \\
15 / 25(60) \\
11 / 25(44)\end{array}$ & $\begin{array}{l}44 / 57(77) \\
35 / 44(80) \\
20 / 44(46)\end{array}$ & $\begin{array}{l}0.30 \\
0.08 \\
0.77 \\
\end{array}$ \\
\hline $\begin{array}{l}\text { Positive } a \beta_{2} \mathrm{GPI} \text { ( } \geq 40 \mathrm{GPL} / \mathrm{MPL} \text { ) } \\
\text { IgG } \\
\text { IgM }\end{array}$ & $\begin{array}{c}7 / 23(18) \\
6 / 7(86) \\
3 / 7(49) \\
\end{array}$ & $\begin{array}{l}10 / 37(18) \\
7 / 10(70) \\
6 / 10(60)\end{array}$ & $\begin{array}{l}0.77 \\
0.45 \\
0.48\end{array}$ \\
\hline $\begin{array}{l}\text { Medications at Database Entry } \\
\text { Aspirin } \\
\text { Warfarin } \\
\text { Hydroxychloroquine }\end{array}$ & $\begin{array}{l}19(50) \\
20(53) \\
14(37)\end{array}$ & $\begin{array}{l}37(65) \\
29(51) \\
55(97)\end{array}$ & $\begin{array}{c}0.15 \\
0.87 \\
0.000^{*}\end{array}$ \\
\hline
\end{tabular}

Conclusions: The analysis of our multicenter aPL database demonstrates that the frequencies of thrombosis and pregnancy morbidity are similar between aPLpositive patients with or without SLE. Half of the patients in both groups had history of at least one "non-criteria" aPL-manifestation; only autoimmune hemolytic anaemia was more frequent in aPL-positive patients with SLE.

\section{REFERENCES:}

[1] Schreiber K, Sciascia S, de Groot PG, Devreese K, Jacobsen S, Ruiz-Irastorza G, et al. Antiphospholipid syndrome. Nat Rev Dis Primers 2018;4:17103

[2] Gómez-Puerta JA, Cervera R. Diagnosis and classification of the antiphospholipid syndrome. J Autoimmun 2014;48-49:20-5.

Disclosure of Interest: None declared

DOI: 10.1136/annrheumdis-2018-eular.6354

\section{AB0553 CHARACTERISTICS OF SYSTEMIC LUPUS ERYTHEMATOSUS AMONG VARIOUS AGE GROUPS: COMPARISON BETWEEN JUVENILE ONSET, ADULT ONSET, AND LATE ONSET SYSTEMIC LUPUS PATIENTS FROM A SINGLE TERTIARY CENTREIN EGYPT}

B.M. Medhat, N. Sobhy, B. Eissa. Rheumatology and Rehabilitation department, Faculty of Medicine-Cairo University, Cairo, Egypt

Background: Systemic lupus erythematosus (SLE) is a complex autoimmune disease with several factors affecting the characteristics of the disease, including age of onset which is one of these major factors. ${ }^{1}$

Objectives: To highlight the differences in disease characteristics among various age groups in an Egyptian cohort from a single tertiary centre.

Methods: Information in this study was derived from medical records of patients admitted to the Rheumatology department in Cairo University from December 2015 to June 2017. All patients fullfilled the SLICC classification criteria of 2012. ${ }^{2}$ Demographic, clinical and serologic characteristics of all patients were recorded. Age of onset was defined as the age at the time of development of manifestations; upon which patients were divided into 3 groups: juvenile onset (JSLE: onset $\leq 16$ years), adult onset: (ASLE: onset 17-50), and late onset lupus (LSLE: onset $>50$ ) patients.

Results: The study included 369 patients, of which $44(11.96 \%)$ were males and $324(88.04 \%)$ were females. The mean age of onset of the cohort was 24.04 \pm 10.15 (7-63) years, while the mean disease duration was $65.6 \pm 58.4(0.5-408)$ months. The study included 75/369 (20.3\%) JSLE, 283/369 (76.6\%) ASLE, and $10 / 369(2.7 \%)$ LSLE patients. The median age of onset of JSLE patients was 13 (11-15), 23 (20-30) in ASLE patients, and 54 (52-58) years in the LSLE group. The median disease duration in JSLE patients was 78 (36-125), 36 (24-84) in ASLE patients, and 12 (9-38) months in LSLE patients. Apart from arthritis, malar rash, and nephritis, there were no differences between the three groups. The prevalence of arthritis was highest among ASLE patients and lowest in JSLE $(p=0.004)$ patients, with LSLE patients showing a comparable prevalence of arthritis to ASLE $(p=0.5)$ and JSLE $(p=0.3)$ patients. On the other hand, JSLE patients showed the highest prevalence of malar rash $(p=0.006)$, as opposed to both ASLE $(\mathrm{p}=0.04)$ and LSLE $(\mathrm{p}=0.004)$ patients; yet ASLE patients showed a substantially high prevalence of malar rash when compared to LSLE patients $(p=0.03)$. Nephritis was most common in JSLE patients $(p=0.007)$ and least common in LSLE patients. Although there was no statistical difference in the prevalence of nephritis between JSLE and ASLE patients $(p=0.1)$, both groups showed a higher prevalence of nephritis than LSLE patients $(p=0.002$ and $\mathrm{p}=0.01$ respectively).

Conclusions: Adult onset SLE patients showed the highest prevalence of arthritis. On the other hand, JSLE patients showed the highest prevalence of nephritis as opposed to LSLE patients with the lowest prevalence, indicating a predilection towards a more severe disease in the former group.

\section{REFERENCES:}

[1] Tucker LB, Uribe AG, Ferna'ndez M, et al. Adolescent onset of lupus results in more aggressive disease and worse outcomes:Results of a nested matched case-control study within LUMINA,a multiethnic US cohort (LUMINA LVII). Lupus 2008; 17:314-322.17

[2 ] Petri M, Orbai AM, Alarcón GS, et al. Derivation and validation of the Sys temic Lupus International Collaborating Clinics classification criteria for systemic lupus erythematosus. Arthritis \& Rheumatology 2012;64:267786.

Disclosure of Interest: None declared

DOI: 10.1136/annrheumdis-2018-eular.6565

\section{AB0554 FACTORS AFFECTING QUALITY OF LIFE IN INDIAN PATIENTS WITH SYSTEMIC LUPUS ERYTHEMATOSUS}

B. Pinto ${ }^{1}$, S. Grover ${ }^{2}$, M. Rathi ${ }^{3}$, A. Dhooria ${ }^{1}$, A. Sharma ${ }^{1} .{ }^{1}$ Internal Medicine; ${ }^{2}$ Psychiatry, ${ }^{3}$ Nephrology, PGIMER, Chandigarh, India

Background: SLE has a profound impact on Quality of Life (QoL). In addition to disease activity and damage, other factors such as fatigue, fibromyalgia and psychiatric comorbidities also influence QoL. ${ }^{1}$ However, there is lack of data in the form of comprehensive assessment of all these factors in the same cohort.

Objectives: To assess the quality of life and its correlates among patients with SLE.

Methods: Using a cross-sectional study design, 144 patients with SLE were assessed for disease activity and damage by using SELENA -SLEDAI and SLICC/ACR damage Index (SDI)), depression (by using Patient Health Questionnaire-9 (PHQ9), anxiety (by using Generalised Anxiety Disorder 7 (GAD7)), fatigue (by using Fatigue severity scale (FSS)) and fibromyalgia (as per using ACR 2010 criteria). QoL was assessed using a generic Qol scale - Short Form 36 (SF-36).2 Statistical analysis was done using STATA version 14.

Results: The study sample included 140 females and 4 males. Mean age of the participants was 32.48 (SD-7.26) years and the mean duration of illness was 3.92 (SD-3.76) years. The mean SELENA SLEDAI and SDI was $3.42 \pm 4.04$ and 0.26 \pm 0.65 respectively. Prevalence of depression (PHQ9 $\geq 10$ ) and anxiety (GAD7 $\geq 10$ ) was $25 \%$ and $22.9 \%$ respectively. Fatigue (FSS $\geq 4$ ) was present in $51.4 \%$. Physical domains of SF36 were affected more often than the mental domains, $71.5 \%$ of the respondents had scores less than 50 in Physical component Summary (PCS) and $61.1 \%$ in Mental Component Summary (MCS) of SF36. No correlation was found between disease activity and damage and various domains of SF36. Depression, anxiety and fatigue had a significant negative correlation with all the domains of SF36 (table 1). On multivariate regression only fatigue was an independent predictor of PCS of QoL.

Abstract AB0554 - Table 1. Spearman Correlation between various domains of SF36 and other variables

\begin{tabular}{|c|c|c|c|c|c|}
\hline & $\begin{array}{l}\text { SELENA } \\
\text { SLEDAI }\end{array}$ & SDI & $\begin{array}{c}\text { Fatigue } \\
\text { (FSS) }\end{array}$ & $\begin{array}{c}\text { Depression } \\
\text { (PHQ9) }\end{array}$ & $\begin{array}{l}\text { Anxiety } \\
\text { (GAD7) }\end{array}$ \\
\hline $\begin{array}{l}\text { Physical } \\
\text { Function }\end{array}$ & -0.1264 & -0.0415 & $-0.3166^{\star \star}$ & $-0.3307^{\star \star}$ & $-0.2987^{\star \star}$ \\
\hline Role Physical & -0.0996 & -0.1082 & -0.3004 ** & $-0.2304^{*}$ & $-0.2286^{*}$ \\
\hline Bodily pain & -0.0913 & -0.1086 & $-0.3902^{\star *}$ & $-0.34^{\star *}$ & $-0.3549^{\star \star *}$ \\
\hline General health & $-0.1681^{*}$ & -0.1356 & $-0.3145^{\star *}$ & $-0.2486^{*}$ & $-0.3115^{\star *}$ \\
\hline Vitality & -0.1589 & -0.0582 & $-0.4135^{\star *}$ & $-0.3595^{\star *}$ & $-0.3795^{\star *}$ \\
\hline Social function & $-0.1645^{*}$ & -0.096 & $-0.2619^{*}$ & $-0.3853^{\star *}$ & $-0.3732^{* *}$ \\
\hline Role Emotional & 0.0471 & -0.0783 & $-0.1905^{*}$ & $-0.2389^{*}$ & $-0.2089^{*}$ \\
\hline Mental Health & -0.0025 & -0.0123 & $-0.2811^{* *}$ & $-0.4545^{\star *}$ & $-0.4873^{* *}$ \\
\hline PCS & $-0.2062^{*}$ & -0.1136 & $-0.3875^{\star *}$ & $-0.2868^{* *}$ & $-0.285^{\star *}$ \\
\hline MCS & -0.0139 & -0.0265 & $-0.2673^{*}$ & $-0.4174^{\star *}$ & $-0.4253^{\star \star}$ \\
\hline
\end{tabular}

${ }^{*} \mathrm{p} \leq 0.05^{* *}=\mathrm{p}<0.001$ 